\title{
Applying gross alpha and beta measurements as an estimate to the total indicative dose of Cambrian-Vendian ground water in Estonia
}

\author{
S. Suursoo, M. Kiisk, A. Jantsikene, K. Isakar and R. Koch \\ Laboratory of Environmental Physics, Institute of Physics, University of Tartu, Riia 142, \\ 51014 Tartu, Estonia
}

\begin{abstract}
Gross alpha and beta measurements are common procedures for screening water samples in order to estimate the level of total indicative dose (TID) from the radionuclides in water. However, it has been pointed out that gross alpha and beta measurements are not suitable for waters containing high concentrations of natural radionuclides, especially Ra-226 and Ra-228. Cambrian-Vendian aquifer system is the major source of public water supply in northern and north-eastern Estonia. The aquifer is known for its high radionuclide concentrations. The main sources of TID are Ra-226 and Ra-228, but the water also contains K-40. Other nuclides from uranium and thorium series may be present as well. A set of Ra-226, Ra-228 and K-40 activity concentrations measured by gammaspectrometry are studied to analyze the applicability of gross alpha and beta measurements in case of Cambrian-Vendian ground water. The calculations indicate that the levels suggested by WHO guidelines are not suitable for the Cambrian-Vendian ground water. Results on the applicability analysis are given.
\end{abstract}

\section{INTRODUCTION}

Gross alpha and beta measurements are common procedures for screening water samples in order to estimate the level of total indicative dose (TID) for public from the radionuclides in water. Both the European Commission's Drinking Water Directive and Estonian national regulations set $0.10 \mathrm{mSv} / \mathrm{year}$ as the maximum value of TID allowed for drinking water $[1,2]$. "Guidelines for drinking water quality" by WHO (2008) suggests a screening level of $0.5 \mathrm{~Bq} / \mathrm{l}$ for gross alpha and $1.0 \mathrm{~Bq} / \mathrm{l}$ for gross beta activity [3]. If gross alpha and gross beta activity concentrations are lower than these values the TID should not exceed $0.10 \mathrm{mSv} /$ year and water should be suitable for drinking.

Nevertheless, many authors have expressed criticism about the suitability of gross alpha and beta measurements for screening [4]. It has been pointed out that gross alpha and beta measurements are not suitable for waters containing high concentrations of natural radionuclides, especially Ra-226 (alpha emitter) and Ra-228 (beta emitter) [5]. Gross beta counting tends to give inadequate results in case of low energy beta emitters such as Ra-228 and $\mathrm{Pb}-210$ when liquid scintillation counting is used to measure gross alpha and beta activities $[4,5]$. The definition of TID does not include tritium, K-40, radon and its progeny in the calculation [1]. However, $\mathrm{K}-40$ and $\mathrm{Pb}-210$ give their contribution to the beta spectrum and Po-210 to the alpha spectrum. This makes it harder to interpret the values of gross alpha and beta activity.

Cambrian-Vendian aquifer system is the major source of public water supply in northern and northeastern Estonia. The aquifer is known for its high radionuclide concentrations. About 250000 people, which is around $19 \%$ of the population in Estonia, consume Cambrian-Vendian ground water. It has been estimated that nearly $91 \%$ of them use water where the TID value exceeds $0.10 \mathrm{mSv} / \mathrm{year}$ [6]. The measurements show that Ra-226 and Ra-228 are the most important sources of TID [6, 7]. CambrianVendian ground water also contains little quantities of Rn-222, Ra-224, Po-210, Pb-210, U-234, U-238, and K-40 [7]. 
The suitability of applying gross alpha and beta measurements to estimate the TID of CambrianVendian ground water is discussed. A database of nuclide specific measurement results obtained in the Institute of Physics, University of Tartu was studied for the applicability analysis. The data contained activity concentrations of Ra-226, Ra-228 and K-40 measured using gammaspectrometry. All the samples were from regions where Cambrian-Vendian ground water might be used (northern and northeastern Estonia).

\section{METHODS}

A gammaspectometrical procedure was used to obtain Ra-226, Ra-228 and K-40 activity concentrations. About 3 liters of water was used for the sample preparation. The water samples were first acidified with concentrated nitric acid to $\mathrm{pH} 1 \ldots 2$. Then the water was evaporated to dryness, and the residue was put into an aluminum can. To obtain the same geometry for all the samples the residue was mixed with $5 \mathrm{~g}$ of Epoxy resin into a homogeneous mass. After about 2 hours of drying the can was hermetically sealed. Measurments were made with a coaxial HPGe gamma-ray spectrometer GEM-35200 (manufacturer EG\&G ORTEC; relative efficiency $42 \%$; resolution $1.75 \mathrm{keV}$ at $1.3 \mathrm{MeV}$ ). Typically, one sample was measured three times. To achieve better statistics the duration of each measurement was about 24 hours. The last measurement was done about 3 weeks after the sealing of the sample to allow the ingrowth of radon-222 and its short lived progeny.

The spectra were analyzed with a program GammaVision (manufacturer EG\&G ORTEC; version 6.07). The activity of Ra-228 was calculated according to the full energy peaks of its daughter nuclide Ac-228. The peaks of $911.20,964.76$ and $968.97 \mathrm{keV}$ were used. The activity of Ra-226 was calculated from its daughter nuclides Pb-214 (242.00, 295.22, $351.93 \mathrm{keV})$ and Bi-214 (609.32, $1120.29,1764.49 \mathrm{keV})$. K-40 activity was obtained from its $1460.60 \mathrm{keV}$ full energy peak.

The efficiency and energy calibrations of the gammaspectrometer were done using a standard calibration sample of $3 \mathrm{~g}$ of IAEA RGU-1 sand (certificated reference material which contains isotopes of uranium, radium and potassium) mixed with $5 \mathrm{~g}$ of Epoxy resin. The background sample was $5 \mathrm{~g}$ of Epoxy resin.

The main advantages of this procedure are its robustness and the fact that many radionuclides can be measured from one sample. However, the procedure is very time consuming and some radionuclides with shorter half lives (e.g. Ra-224 with a half life of 3.66 days) may decay before the sample gets ready for measurement.

All together 44 samples were analyzed for the Ra-226 and Ra-228 activity concentrations. In 30 samples K-40 activity concentration was also determined. The measurements were performed during the period November 2008 until December 2010.

\section{RESULTS AND DISCUSSION}

\subsection{Results}

Summary of the measurement results by gamma analysis is given in Table 1 . The total indicative dose is calculated on the bases of Ra-226 and Ra-228 activity concentrations according to formula (1) [3]:

$$
D=V \cdot A_{R a 226} \cdot h(g)_{R a 226}+V \cdot A_{R a 228} \cdot h(g)_{R a 228}
$$

where $\quad V$ is the average water consumption by an adult (730 1/year),

$A_{R a 226}$ and $A_{R a 226}$ are activity concentrations of Ra-226 and Ra-228,

$h(g)_{R a 226}$ and $h(g)_{R a 228}$ are dose coefficients for Ra-226 and Ra-228 (see Table 3.)

TID value exceeded the $0.10 \mathrm{mSv} /$ year limitation in case of 32 samples. 
Table 1. Summary of the activity concentrations and TID values of the analyzed samples. TID is calculated from Ra-226 and Ra-228 activity concentrations.

\begin{tabular}{|c|c|c|c|c|c|c|c|c|}
\hline & \multicolumn{4}{|c|}{ All measured samples } & \multicolumn{4}{c|}{$\begin{array}{c}\text { Samples where } \\
\text { TID }>\text { 0.10 mSv/yr }\end{array}$} \\
\cline { 2 - 10 } & $\begin{array}{c}\text { Ra-226 } \\
\mathbf{m B q} / \mathbf{l}\end{array}$ & $\begin{array}{c}\text { Ra-228 } \\
\mathbf{m B q} / \mathbf{l}\end{array}$ & $\begin{array}{c}\text { K-40 } \\
\mathbf{m B q} / \mathbf{l}\end{array}$ & $\begin{array}{c}\text { TID } \\
\mathbf{m S v} / \mathbf{y r}\end{array}$ & $\begin{array}{c}\text { Ra-226 } \\
\mathbf{m B q} / \mathbf{l}\end{array}$ & $\begin{array}{c}\text { Ra-228 } \\
\mathbf{m B q} / \mathbf{l}\end{array}$ & $\begin{array}{c}\text { K-40 } \\
\mathbf{m B q} / \mathbf{l}\end{array}$ & $\begin{array}{c}\text { TID } \\
\mathbf{m S v} / \mathbf{y r}\end{array}$ \\
\hline $\begin{array}{c}\text { No of } \\
\text { samples }\end{array}$ & 44 & 44 & 30 & 44 & 32 & 32 & 18 & 32 \\
\hline Average & 247 & 236 & 504 & 0.17 & 312 & 304 & 574 & 0.22 \\
\hline Max & 696 & 707 & 1212 & 0.48 & 696 & 707 & 1212 & 0.48 \\
\hline Min & 0 & 0 & 160 & 0 & 75 & 127 & 160 & 0.11 \\
\hline $\begin{array}{c}\text { Standard } \\
\text { deviation }\end{array}$ & 172 & 180 & 342 & 0.118 & 155 & 163 & 371 & 0.102 \\
\hline
\end{tabular}

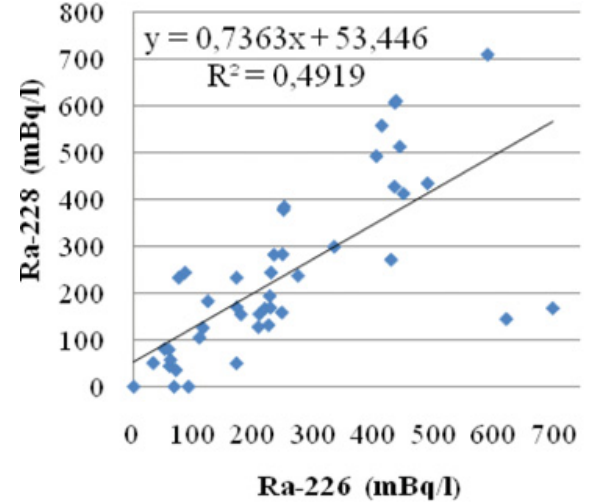

a)

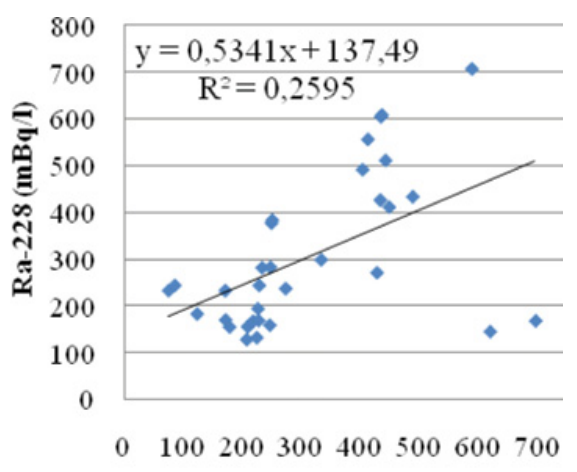

$\operatorname{Ra}-226(\mathbf{m B q} / \mathbf{l})$

b)

Figure 1. Correlation between the activity concentrations of Ra-226 and Ra-228: a) taking into account all the measured water samples; b) in case of the water samples where TID exceeded $0.10 \mathrm{mSv} /$ year.

In order to analyze the applicability of gross alpha and beta activity measurements we need to know what are the main alpha and beta emitting dose contributors present in the water and is there a correlation between their concentrations. As stated before, the main dose contributors in case of Cambrian-Vendian water are radium isotopes Ra-226 and Ra-228 [6, 7]. The correlation between their activity concentrations was studied. The statistical analyses were done using two data sets. First, all the measured samples were taken into account. Subsequently, only the samples where the TID value exceeded $0.10 \mathrm{mSv} / \mathrm{year}$ were used.

The results can be seen in Figure 1 and Table 2. When considering all the measured water samples a weak correlation between the activity concentrations of the two radium isotopes was found (coefficient of determination $\mathrm{R}^{2}=0.4919$ ). According to the regression analysis the slope of the model proved to be statistically significant, but the value of the intercept is not statistically significant.

The correlation between Ra-226 and Ra-228 activity concentrations is weaker when only the samples where the TID value exceeded $0.10 \mathrm{mSv} /$ year are taken into account $\left(\mathrm{R}^{2}=0.2595\right)$. However, the linear regression model still proved to be statistically significant (see Table 2).

\subsection{Screening levels for gross alpha and beta activity}

If water would contain only Ra-226, its activity concentration of $0.5 \mathrm{~Bq} / 1$ would cause a total indicative dose of $0.10 \mathrm{mSv} /$ year (calculated according to Formula 1 ). If the only radionuclide in the water would 
Table 2. Results of the regression analysis.

\begin{tabular}{|c|c|c|c|c|c|c|c|c|c|}
\hline \multicolumn{4}{|c|}{ All measured samples } & \multicolumn{5}{c|}{ Samples where TID > 0.10 mSv/yr } \\
\hline & $\begin{array}{c}\text { Coeffi- } \\
\text { cients }\end{array}$ & $\begin{array}{c}\text { Standard } \\
\text { error }\end{array}$ & \multicolumn{2}{|c|}{ P-value } & & $\begin{array}{c}\text { Coeffi- } \\
\text { cients }\end{array}$ & $\begin{array}{c}\text { Standard } \\
\text { error }\end{array}$ & \multicolumn{2}{c|}{ P-value } \\
\hline $\begin{array}{c}\text { Inter- } \\
\text { cept }\end{array}$ & 53.446 & 34.622 & 0.130 & $\begin{array}{c}\text { not sig- } \\
\text { nificant }\end{array}$ & $\begin{array}{c}\text { Inter- } \\
\text { cept }\end{array}$ & 137.492 & 57.281 & 0.023 & $\begin{array}{c}\text { signi- } \\
\text { ficant }\end{array}$ \\
\hline Slope & 0.7363 & 0.1155 & $\begin{array}{c}1.1 \mathrm{E}- \\
07\end{array}$ & $\begin{array}{c}\text { signi- } \\
\text { ficant }\end{array}$ & Slope & 0.5341 & 0.1647 & 0.0029 & $\begin{array}{c}\text { signi- } \\
\text { ficant }\end{array}$ \\
\hline
\end{tabular}

be Ra-228, $1 \mathrm{~Bq} / \mathrm{l}$ of beta activity would cause a dose of $0.50 \mathrm{mSv} / \mathrm{year}$. This simple calculation shows clearly that WHO guidelines are not applicable for waters where the dose is mainly caused by radionuclides with high dose coefficients, such as Ra-228.

To find more suitable screening levels for Cambrian-Vendian ground water we take into account that both radium isotopes are present in the water. Although the correlations are weak, the linear regression models calculated in section 3.1 can be used as estimates of the relationship between Ra-226 and Ra228 activity concentrations. When combining the TID formula (Formula 1) with the regression model we get the following equation system:

$$
\begin{gathered}
D=V \cdot A_{R a 226} \cdot h(g)_{R a 226}+V \cdot A_{R a 228} \cdot h(g)_{R a 228} \\
A_{R a 228}=a \cdot A_{R a 226}+b
\end{gathered}
$$

where $D$ equals $0.10 \mathrm{mSv} / \mathrm{year}, a$ and $b$ are the values of slope and intercept in the linear regression model.

For simplification we assume that Ra-226 is the only alpha emitter and Ra-228 is the only beta emitter in the water. Then $A_{R a 226}$ and $A_{R a 228}$ can be interpreted as estimates of the screening levels for gross alpha and beta activity concentrations respectively.

First, the regression model considering all the measured water samples was used. In that case, the activity concentrations that would give a dose of $0.10 \mathrm{mSv} / \mathrm{year}$ are $127 \mathrm{mBq} / \mathrm{l}$ for alpha and $147 \mathrm{mBq} / \mathrm{l}$ for beta. Secondly, the regression model considering only the samples where TID exceeds $0.10 \mathrm{mSv} / \mathrm{year}$ was applied. The critical activity concentrations are now $65 \mathrm{mBq} / \mathrm{l}$ for alpha emitters and $172 \mathrm{mBq} / \mathrm{l}$ for beta emitting nuclei. The levels calculated using different regression models vary a lot as the correlation between the content of radium isotopes is rather weak. In case of the screening level for gross alpha activity, the more conservative value $(65 \mathrm{mSv} /$ year) should be a better estimate as it is calculated on the bases of a critical group of water samples (TID $>0.10 \mathrm{mSv} / \mathrm{year}$ ).

Cambrian-Vendian ground water also contains other alpha and beta emitters although Ra-226 and Ra-228 are the main contributors to the TID. This makes finding concrete screening levels a complex task. Measurement results show that significant amounts of K-40 are present in Cambrian-Vendian ground water (see Table 1). The activity concentration of K-40 is not taken into account in TID calculations [1] because it does not accumulate in the body [3] and has a low dose coefficient (see Table 3). However, K-40 as a beta emitter may give a considerable contribution to the beta spectrum. At the same time its activity concentration varies a lot from sample to sample - the standard deviation in case of 30 measured water samples was $342 \mathrm{mBq} / \mathrm{l}$ (see Table 1). The regression analysis between the activity concentrations of K-40, Ra-226 and Ra-228 did not show any significant correlation with neither of the radium isotopes (see Figure 2). The correlation was even weaker when only the samples where TID value exceeded $0.10 \mathrm{mSv} /$ year were taken into account. These reasons indicate that gross beta activity measurements are not applicable in case of Cambrian-Vendian ground water.

Not much data is available on the activity concentrations of other nuclides from the uranium and thorium series in Cambrian-Vendian ground water. A few measurements that have been done to determine the activity of Po-210 and $\mathrm{Pb}-210$ [7,9] indicate that in some cases these nuclides may 
Table 3. Dose coefficients and decay modes of natural radionuclides which may be present in ground water [8].

\begin{tabular}{|c|c|c|}
\hline Radio-nuclide & Dose coefficient Sv/Bq & Decay mode \\
\hline $\mathrm{K}-40$ & $6.20 \mathrm{E}-09$ & $\beta$ \\
\hline $\mathrm{Ra}-226$ & $2.80 \mathrm{E}-07$ & $\alpha$ \\
\hline $\mathrm{Ra}-228$ & $6.90 \mathrm{E}-07$ & $\beta$ \\
\hline $\mathrm{Ra}-224$ & $6.50 \mathrm{E}-08$ & $\alpha$ \\
\hline Po-210 & $1.20 \mathrm{E}-06$ & $\alpha$ \\
\hline Pb-210 & $6.90 \mathrm{E}-07$ & $\beta$ \\
\hline $\mathrm{U}-234$ & $4.9 \mathrm{E}-08$ & $\alpha$ \\
\hline $\mathrm{U}-238$ & $4.5 \mathrm{E}-08$ & $\alpha$ \\
\hline
\end{tabular}

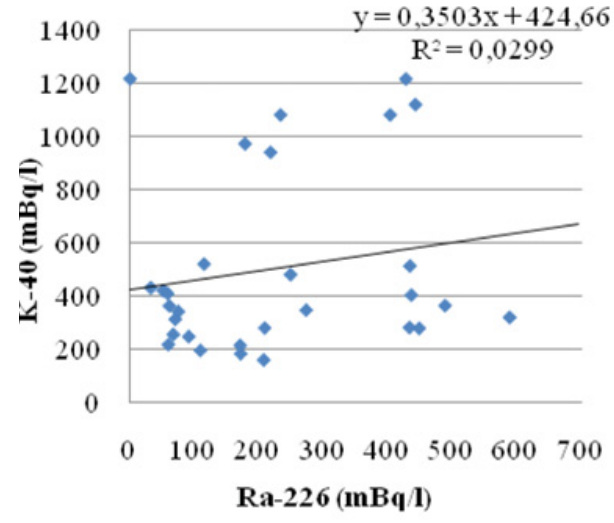

a)

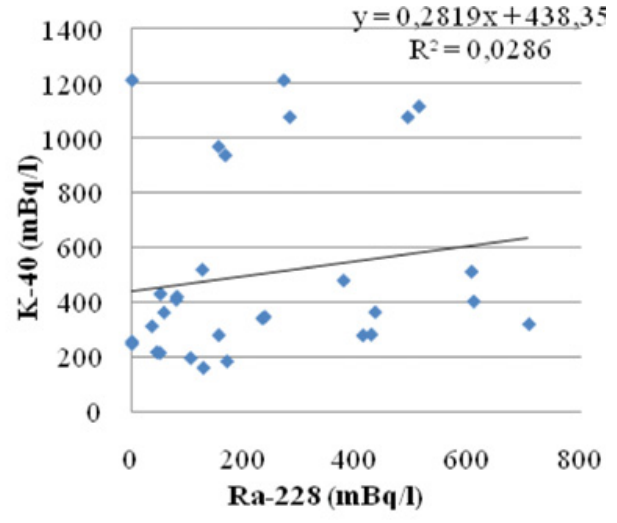

b)

Figure 2. Correlation between the activity concentrations of radium isotopes and K-40 taking into account all the measured water samples. a) Correlation between Ra-226 and K-40. b) Correlation between Ra-228 and K-40.

give a notable extra dose, especially considering the high dose coefficient of Po-210 (see Table 3). In 2008 Geological Survey of Estonia, LLT lead a research where Po-210 and Pb-210 activities were determined in six Cambrian-Vendian water samples [9]. In one sample the dose caused by Po-210 even exceeded $0.10 \mathrm{mSv} / y e a r$. In the rest of the samples the dose by Po-210 and Pb-210 was in a range of $0.01 \mathrm{mSv} / y e a r$. According to the definition of TID Po-210 and $\mathrm{Pb}-210$ as progeny of radon are excluded from TID calculations [1]. However, European Commission has suggested that Po-210 and Pb-210 should be taken into account when they pose a comparable or a higher radiation risk than some natural radionuclides monitored in accordance with the Drinking Water Directive [10]. This might be the case in Cambrian-Vendian ground water, which means that the activities of Po-210 and Pb-210 should be considered when setting screening levels for gross alpha and beta activity.

It was stated above that gross beta activity values are not applicable for Cambrian-Vendian ground water samples. The situation is not as complex in case of gross alpha activity screening levels. Previous measurements show that besides Po-210, Cambrian-Vendian ground water may contain U-234, U-238 and Ra-224 [7]. The latter nuclides give a contribution to the alpha spectrum but their influence on the dose value is much smaller as the dose coefficients are in the order of magnitudes lower than for Ra-226 (see Table 3). Nevertheless, gross alpha activity measurements tend to have little value. The screening level $65 \mathrm{mBq} / \mathrm{l}$ calculated above is so low that nearly all Cambrian-Vendian water samples would exceed it. Gross alpha analysis would not give any advantages or possibilities to save time. 


\section{CONCLUSIONS}

The calculations indicate that the screening levels for gross alpha and beta activities suggested by WHO guidelines are not suitable for the Cambrian-Vendian ground water. The screening levels should be in an order of magnitude lower than the values set by $\mathrm{WHO}$ as the main radionuclides contributing to the TID are Ra-226 and Ra-228 which have high dose coefficients. Water from Cambrian-Vendian aquifer system also contains K-40, its concentrations tend to be very variable. K-40 may give a significant contribution to the beta spectrum and its activity may hide the activity of other beta emitters with high dose coefficients. Therefore, gross beta activity measurements are not applicable for evaluating TID values in case of Cambrian-Vendian growndwater. Gross alpha activity measurements proved also to be unusable, because the screening level value $(65 \mathrm{mBq} / \mathrm{l})$ obtained by the calculations is so low that almost all the water samples would exceed it.

\section{Acknowledgments}

The first author wishes to thank Archimedes Foundation for funding the travelling costs to attend the conference ICRER 2011. This work has been partially supported by Estonian Science Foundation grant no 6505.

\section{References}

[1] European Commission, ,“Council Directive 98/83/EC of 3 November 1998 on the quality of water intended for human consumption" (1998).

[2] Estonian Minister of Social Affairs, regulation "Sotsiaalministri määrus nr 81 16. juunist 2005. Sotsiaalministri 31. juuli 2001. a määruse nr 82 "Joogivee kvaliteedi- ja kontrollinõuded ning analüüsimeetodid" muutmine." (2005),

[3] World Health Organization, "Guidelines for drinking-water quality, III edition" (WHO, Geneva, 2008).

[4] Chalupnik S., Gerstmann U., Mielnikow A., "Gross alpha and beta activity measurements by LSC - the problem of interpretation", presented at LSC 2010 Advantages in Liquid Scintillation Spectrometry, Paris, France, 6-10 September 2010.

[5] Forte M., Rusconi R., Costantino S., Badalamenti P., Lunesu D., Sgorbati G., "Gross alpha and beta measurement by LSC in waters: advantages, problems and limitations", presented at LSC 2010 Advantages in Liquid Scintillation Spectrometry, Paris, France, 6-10 September 2010.

[6] Forte M., Rusconi R., Trotti F., Caldognetto E., Airoldi R., Realini F., Risica S., Bagnato L., Twinning Light Contract EE06-IB-TWP-ESC-03, "Estimation of concentrations of radionuclides in Estonian ground waters and related health risks. Final Report" (Agenzia Regionale per la Protezione dell'Ambiente della Lombardia, Milano, 2010)

[7] Kiisk M., Suursoo S., Isakar K., Koch R., "Relevant Radionuclides in Estonian Drinking and Ground Waters - Measurements Techniques and Activity Concentrations", presented at International Conf. of Radioecology and Environmental Radioactivity 2011, Hamilton, Canada, 20-24 June 2011.

[8] United Nations Scientific Committee on the Effects of Atomic Radiation, "Report Vol. I Sources and effects of ionizing radiation. Annex A: Dose assessment methodologies" (2000)

[9] Savitskaja L., Savva V., "Uuring Po-210 ja Pb-210 sisalduse kohta Kambriumi-Vendi veekompleksi põhjavees" in Eesti Geoloogiakeskuse aastaraamat 2008, edited by M. Kukk (Eesti Geoloogiakeskus, Tallinn, Estonia, 2009)

[10] European Commission, "Commission Recommendation of 20 December 2001 on the protection of the public against exposure to radon in drinking water supplies (2001/928/Euratom)" (2001). 